REVIEW ARTICLE

\title{
Examination of nutritional knowledge levels of physical education and sports stakeholders in gender variable: A systematic review and meta-analysis
}

\author{
Şakir Tüfekçi ${ }^{1 \mathrm{ABCDE}}$, Hulusi Böke ${ }^{\mathrm{ABCD}}$, Oğuzhan Altungül ${ }^{3 \mathrm{ABC}}$ \\ ${ }^{1}$ Sports Management Department, Malatya, Turkey \\ ${ }^{2}$ Ministry of Education, Yaşar Öncan Secondary School, Malatya, Turkey \\ ${ }^{3}$ Sports Management Department, Elazığ, Turkey
}

Authors' Contribution: A - Study design; B - Data collection; C - Statistical analysis; D - Manuscript Preparation; E - Funds Collection.

\begin{abstract}
Background Nutrition knowledge is related to dietary behavior in athletes. Therefore, it may also have an impact on and Study Aim performance. Athletes with better nutrition knowledge have more healthy dietary habits. This metaanalysis study focused on the impact of gender on the nutrition knowledge levels of physical education and sports stakeholders.

Material and This study adopted a meta-analysis research design, which is used to analyze, synthesize, and interpret Methods quantitative findings from an array of studies through advanced statistical techniques. A meta-analysis involves combining the findings of studies carried out in different places and at different times on the same topic and obtaining a quantitatively accurate result based on a large sample. This study employed the Comprehensive Meta-Analysis (CMA, v. 2.0) to determine effect sizes and the variance of each study and to compare groups. Cohen's kappa intercoder reliability and outlier tests were performed using the Statistical Package for Social Sciences (SPSS).

Results: $\quad$ We focused on 31 studies with a total sample size of 4575 . We calculated the effect size of each study. We found a statistically significant effect size in favor of female stakeholders $(d=0.15 ; 95 \% \mathrm{Cl}-0.22-0.09)$ in the fixed effects model, which was a weak result according to Cohen's classification. We determined a statistically significant effect size in favor of female stakeholders $(d=0.15 ; 95 \% \mathrm{Cl}-0.29-0.01)$ in the randomeffects model. These results suggest a slight difference in nutrition knowledge levels between male and female physical education and sports stakeholders. This result can pave the way for further research.

Conclusions It is understood from the physical education and sports stakeholders that there is a weak difference in the nutritional knowledge levels of women compared to men. It is thought that people who study on sports nutrition and nutrition programs will benefit from the present finding. In addition, it is estimated that the researches to be carried out on the relevant subject will take the current study as a reference.

Keywords: nutrition knowledge, gender, meta-analysis, sports nutrition
\end{abstract}

\section{Introduction}

All people consume food at the right amount and at the right time to satisfy their needs for energy and nutrients they need to stay healthy and have a high-quality life [1]. People take in nutrients for growth, survival, and good health. Health depends on a balanced diet depending on consuming enough nutrients for energy. Malnutrition or undernutrition causes underdevelopment and poor health [2]. Food is a basic need, and meeting that need is essential to good health and paves the way for meeting other basic needs [3].

Nutrition education programs are based on the premise that superior nutrition knowledge can translate into better dietary and lifestyle choices. A large-scale survey in the United Kingdom shows a positive correlation between nutrition knowledge and intake of less fat and more fruit and vegetables [4]. Nutrition knowledge determines what food athletes choose to consume [5]. Studies on athletes focus on general concepts of health protection [6,7] and sports-specific nutrition knowledge [8]. Other factors are

๑) Şakir Tüfekçi, Hulusi Böke, Oğuzhan Altungül, 2021

doi:10.15561/20755279.2021.0506 related to psychological, social, economic parameters, lifestyle, beliefs, or food choices. There is a growing body of research on the nutrition knowledge of athletes [9-11].

Nutrition knowledge is related to dietary behavior in athletes. Therefore, it may also have an impact on performance. Athletes with better nutrition knowledge have more healthy dietary habits $[9,10]$. Nutrition education programs are designed to increase nutrition knowledge because it is expected to help athletes develop better dietary habits, become healthier, and improve their performance. Athletes know about nutrition as much as or more than the general population. Female athletes with nutrition knowledge perform better and participate more in physical sports than their male counterparts [12]. Some evidence suggests that educated or elite athletes and female athletes have better nutrition knowledge than male athletes. Athletes may have more nutrition knowledge than non-athletes. These results are primarily derived from descriptive studies and require validation based on well-defined and designed studies and populations [9].

In their systematic review, Heaney et al. found that women had more nutrition knowledge than men [9]. 
Zawila et al. evaluated the sports nutrition knowledge and attitudes of 60 female undergraduate cross-country runners in two states. They reported that the runners scored greater than $70 \%$ on iron, functional foods, and hydration [13]. Female student-athletes learn about sports nutrition from university courses and nutritionists, whereas male studentathletes learn about it from strength and conditioning coordinators and athletic trainers. Besides, both male and female athletes turn to magazines, family members, and coaches as reliable sources of information [14].

Earlier studies have reported different results concerning the effect of gender and ultra-resilience disciplines on nutrition knowledge [11]. Jessri et al. found that female athletes had significantly more nutrition knowledge than male athletes [15]. On the other hand, Arazi and Hosseini determined that male athletes had significantly more nutrition knowledge than noncollegiate female athletes [16]. Dunn et al. concluded that female athletes scored slightly higher than their male counterparts in the Nutrition and Knowledge Questionnaire and each recommendation section [17]. However, Rash et al. and Rosenbloom, Jonnalagadda, and Skinner did not find any difference in nutrition knowledge levels between male and female athletes [8, 18]. Canbolat and Çakıroğlu reported that male trainers had higher nutrition knowledge scores than female trainers [19]. Çongar and Özdemir did not find a significant difference in nutrition knowledge levels between male and female physical education teachers [20].

Research shows that athletes generally see their trainers as a source of nutrition knowledge [21-23], which shows how important an educational role trainers and teachers play. This paper aimed to take into account all the stakeholders of physical education and sports (professional athletes, students-athletes, trainers, teachers, etc.) and show the big picture in terms of nutrition knowledge.

Most studies on education in Turkey and other countries look into the effect of gender on nutrition knowledge. Gender is also regarded as an important factor that determines results or indicates a correlation. An event, phenomenon, or situation is regarded as a "variable" [24,25]. A meta-analysis study is needed to determine the effectiveness of studies investigating the impact of gender on the nutrition knowledge of physical education and sports stakeholders. This meta-analysis will fill a gap in the literature on the impact of gender on the nutrition knowledge of athletes and will offer a new perspective to nutritionists and teams working on athlete diet. We think that our results can be used in nutrition training activities. They will also guide sports nutrition trainers and help them carry out their training activities more consciously. This meta-analysis study focused on the impact of gender on the nutrition knowledge levels of physical education and sports stakeholders. In addition, within the scope of the meta-analysis study, it was tested whether some variables that are thought to affect the overall effect size and which are frequently presented in the studies of the authors in the literature, have a moderator effect.

\section{Material and Methods}

\section{Data collection.}

The sample consisted of scientific articles, master's thesis, and Ph.D. dissertations. The databases ULAKBIM, YÖK, Google Akademik, EBSCOhost, and Web of Science were screened to access them. The inclusion criteria were as follows:

Criterion 1: Published or unpublished scientific articles, master's thesis, and Ph.D. dissertations.

Criterion 2: Appropriate research design: The included studies should adopt a screening design and use gender as an independent variable in order for us to calculate effect sizes.

Criterion 3: To calculate the effect sizes, we focused on fundamental statistical data (mean, standard deviation, sample size) on the effect of gender on the nutrition knowledge levels of physical education and sports stakeholders.

Criterion 4: Publication year: Studies conducted between 2000 and 2020.

Criterion 5: Language: Turkish or English.

We used a PRISMA flow diagram to collect data (Figure 1) [26].

Study design:

This study adopted a meta-analysis research design, which is used to analyze, synthesize, and interpret quantitative findings from an array of studies through advanced statistical techniques. A meta-analysis involves combining the findings of studies carried out in different places and at different times on the same topic and obtaining a quantitatively accurate result based on a large sample [27-31]. This study employed the Comprehensive Meta-Analysis (CMA, v. 2.0) to determine effect sizes and the variance of each study and to compare groups. Cohen's kappa intercoder reliability and outlier tests were performed using the Statistical Package for Social Sciences (SPSS).

Data analysis:

Statistical software packages were used to calculate effect sizes and the variance of each study and to conduct between-group comparisons. The standardized effect size developed by Cohen was used to calculate the effect size of each study [32]. Men consisted of the experimental group, while women consisted of the control group. Therefore, a positive effect size favored man, while a negative one favored woman. The data were analyzed at a significance level of 0.05 because all studies took 0.05 as the significance level.

The second researcher coded the interview data of four randomly selected participants to check the coding and determine whether the coding agreement was adequate. Intercoder reliability was calculated using the formula $[$ Reliability $=$ (number of agreements) $/$ (number of agreements + number of disagreements $) * 100]$ suggested by Miles and Huberman. The intercoder reliability was 0.93 . An intercoder agreement greater than 0.70 indicates adequate reliability [33]. Establishing coding protocol reliability is critical for a meta-analysis [34,35]. Therefore, two experts (faculty members with a Ph.D. 


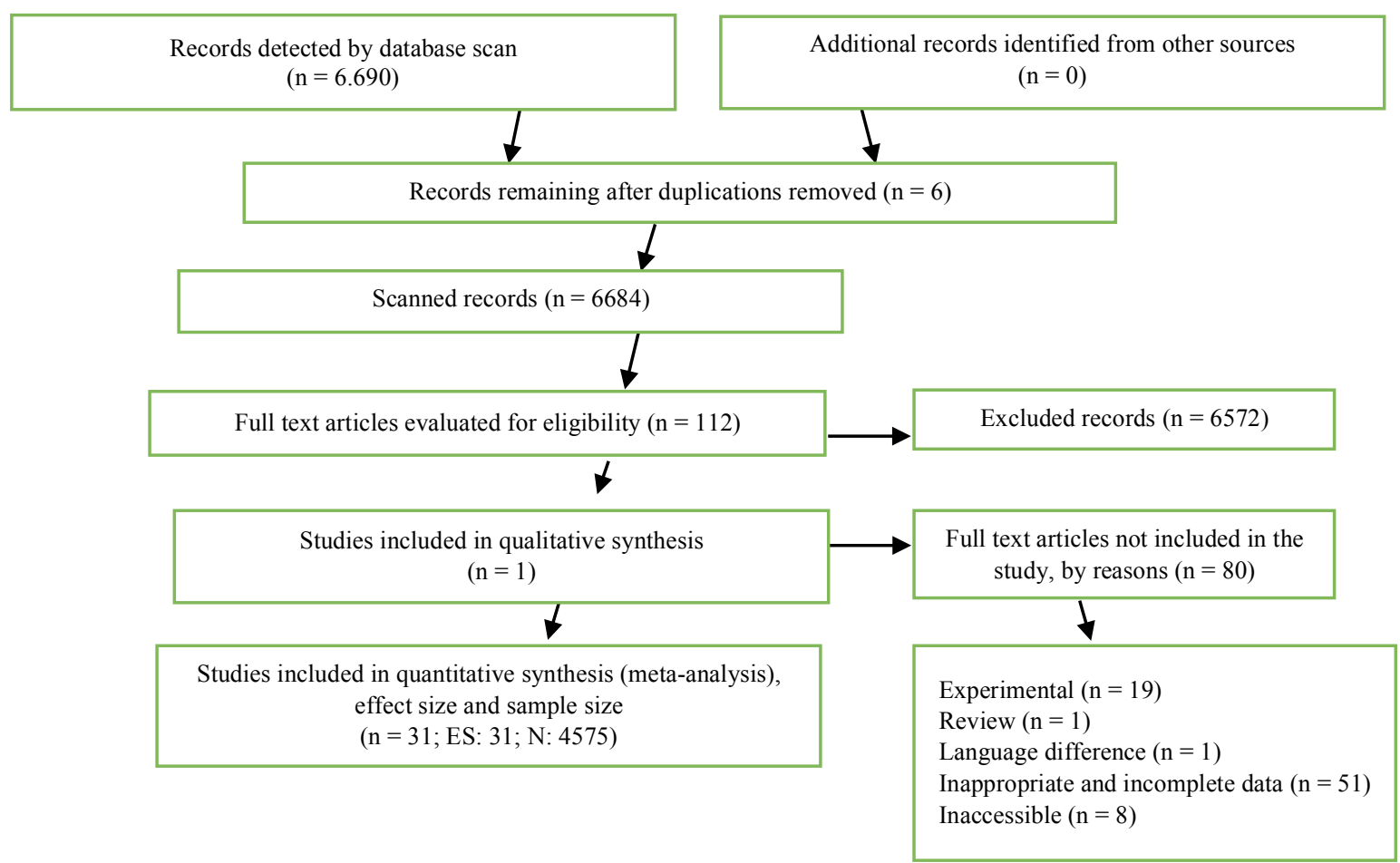

Figure 1. PRISMA flow diagram

in physical education who teach in related programs of sports sciences faculties) filled out the codings separately. Afterward, they came together and discussed the parts on which they disagreed until they reached a consensus. The intercoder agreement was $80.2 \%$. Some researchers [34] argue that Cohen's Kappa statistic is more reliable given the chance factor due to the lack of options in agreement levels based on intercoder frequency data. The intercoder reliability index was 0.78 , indicating almost perfect agreement [36-38].

Hunter and Schmidt argue that a researcher should pay attention to studies with very different effect sizes when determining outliers because he/she cannot fix a bad dataset without excluding those studies [39]. Hedges and Olkin state that removing an outlier from a dataset is the right decision provided that the overall average is not affected and that the model fit improves. They propose various methods for detecting outliers. According to their methods, studies deviating relatively excessively in forest plot axes are outliers [40]. We used forest plot, standard residuals, z-score (4.80), and heterogeneity $(\mathrm{Q}=1083.73,10 ; \mathrm{p}<0.57)$ to identify outliers. All in all, we did not detect any outliers. Therefore, the sample consisted of 31 studies.

\section{Results}

We analyzed the data derived from the studies to seek answers to the research question. This section addressed the publication bias, fixed-effects model, homogeneity, random-effects model, and moderator analysis findings.

Most individual effect sizes were grouped symmetrically in the funnel (Figure 2). Moreover, the individual effect sizes were grouped around the middle line showing the overall effect size. Figure 2 shows no publication bias. However, we also had to analyze the publication bias statistics because not all individual effect sizes were grouped symmetrically in the funnel. Table 1 shows the statistics as a way to address publication bias.

Rosenthal's Safe N Test shows that the meta-analysis result was statistically significant $(p=.000)$ (Table 1$)$. We needed 136 more studies with a zero-effect size in order for the meta-analysis result to be non-significant ( $\mathrm{p}>$ .05 ). The sample consisted of studies we accessed after a rigorous search (qualitative, quantitative, and theoretical) in all accessible library catalogs and digital databases. Kendall's Tau coefficient (Begg and Mazumdar Rank Correlations) was statistically insignificant (-.00 ve $p=$ $.05)$, indicating the absence of publication bias. Egger's Linear Regression $(\mathrm{p}=.92>.05)$ also showed no publication bias (95\% confidence interval).

Combined findings according to fixed and random effects model (tabl.2).

According to the fixed effects model, women had slightly more nutrition knowledge than men. However, according to Cohen's classification, gender had a weak effect because the effect size was less than 0.20 [41] (fig.3).

The homogeneity test result was Q=125,390 (Q-statistics). Thirty degrees of freedom were 43.773 $\left(\mathrm{X}^{2}\right.$ Table 2). The null hypothesis of homogeneity of the distribution of effect sizes was rejected in the fixed effects model because the Q-statistic value exceeded the critical value of the chi-square distribution. In other words, the distribution of effect sizes had heterogeneity according to the fixed-effects model. The $\mathrm{I}^{2}$ value, which complements the Q statistic, yields more accurate results regarding 


\section{Funnel Plot of Standard Error by Std diff in means}

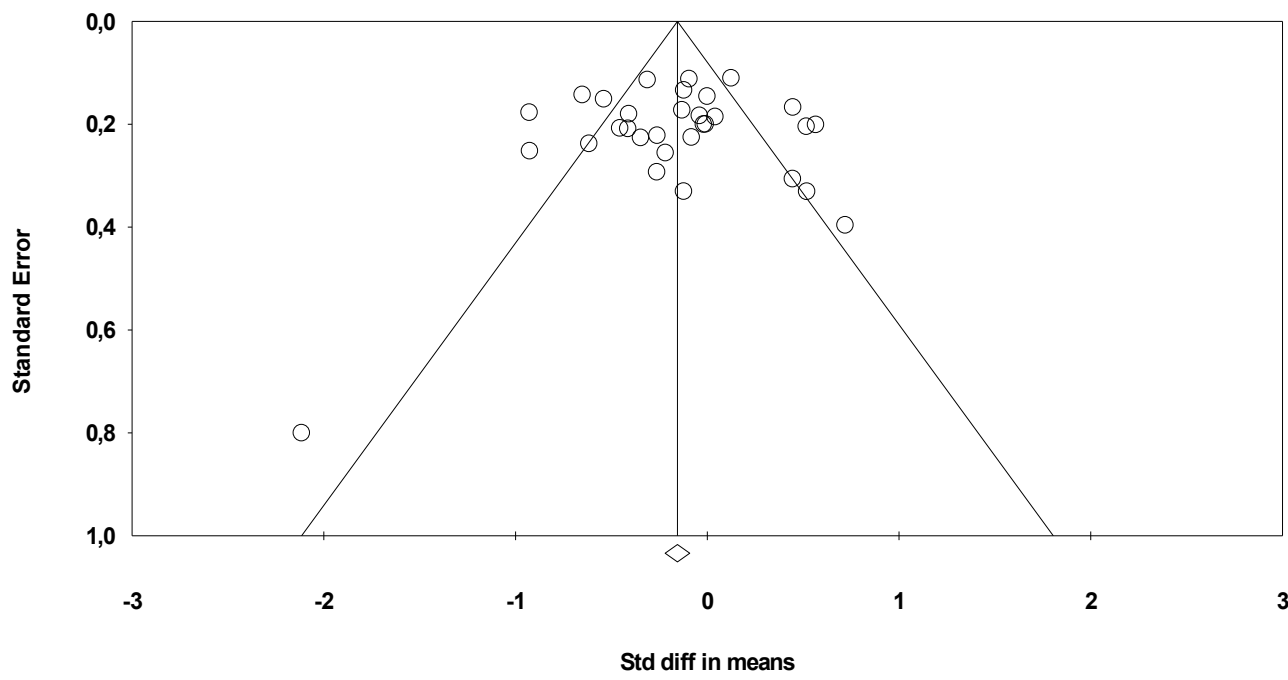

Figure 2. A funnel plot of effect sizes of studies on the impact of gender on nutrition knowledge levels of physical education and sports stakeholders

Table 1. Tests results for publication bias of studies subjected to meta-analysis

\begin{tabular}{lll}
\hline Tests & Test data & -4.53 \\
& Z-value for observed studies & .00 \\
Rosenthal's Safe N Test & P-value for observed studies & .05 \\
& Alpha & 2 \\
& Tails & 1.95 \\
& Z for alpha & 31 \\
& Number of observed studies & 136 \\
\hline & Safe N (FSN) & -.00 \\
\hline & Tau & .05 \\
& Z-value for Tau & .47 \\
& P-value (one-tailed) & .95 \\
\hline & P-value (two-tailed) & 1.12 \\
& Standard Error & -2.41 \\
& $95 \%$ lower limit (one-tailed) & 2.19 \\
\hline
\end{tabular}

Table 2. Combined findings according to fixed and random effects model and homogeneity test

\begin{tabular}{|c|c|c|c|c|c|c|c|c|c|c|c|}
\hline \multirow[t]{2}{*}{ Model } & \multicolumn{5}{|c|}{ Effect size and $95 \%$ confidence interval } & \multicolumn{3}{|c|}{ Null hypothesis } & \multicolumn{3}{|c|}{ Heterogeneity } \\
\hline & 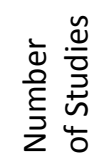 & 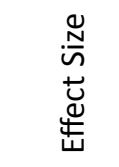 & 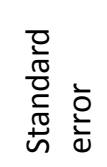 & 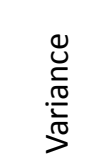 & 㐫 & 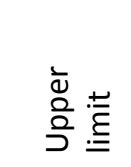 & $\frac{\frac{0}{2}}{\frac{\pi}{N}}$ & ○ & $\frac{\frac{0}{2}}{\frac{\pi}{0}}$ & $\frac{\widetilde{\sigma}}{L^{\circ}}$ & $\simeq$ \\
\hline Fixed & 31 & -0.156 & 0.03 & 0.00 & -0.22 & -0.09 & -4.73 & 0.00 & 125.39 & 30 & 76.07 \\
\hline Random & 31 & -0.152 & 0.07 & 0.00 & -0.29 & -0.01 & -2.15 & 0.03 & & & \\
\hline
\end{tabular}


Meta Analysis

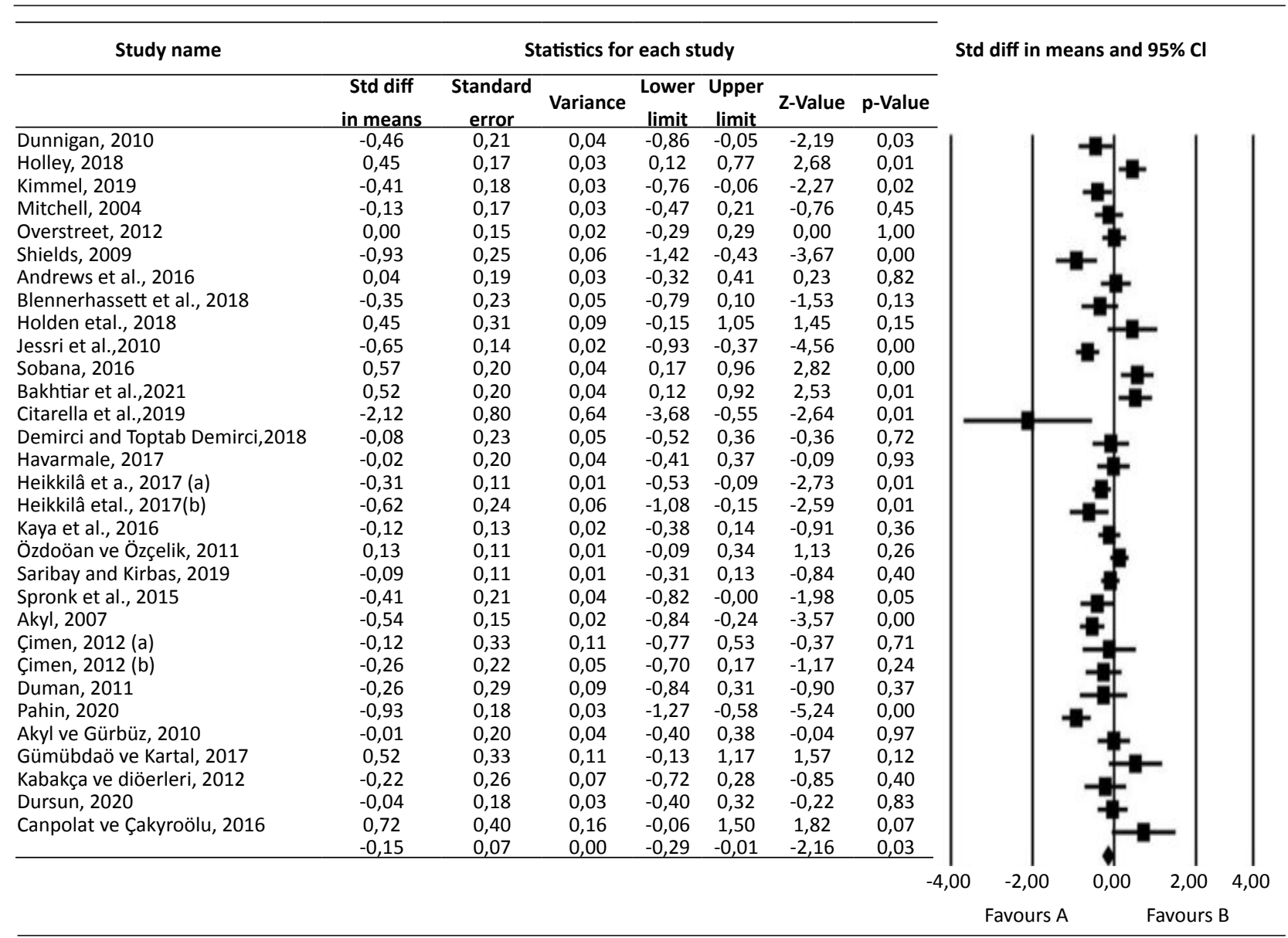

Figure 3. Forest plot

Table 3. Categorical moderator results on the effect of gender on nutrition knowledge

\begin{tabular}{lllllll}
\hline Moderator & $\mathbf{k}$ & $\mathbf{d}$ & $\mathbf{S E}$ & $\% 95 \mathrm{Cl}$ & $\mathbf{Q}_{\text {hetween }}$ & $\mathbf{p}$ \\
\hline Research type & $31^{* *}$ & & & & 0.19 & $0.66^{*}$ \\
$\quad$ Scientific article & 25 & -0.16 & 0.03 & $-0.23 ;-0.08$ & & \\
$\quad$ Master's thesis & 6 & -0.14 & 0.07 & $-0.28 ; 0.00$ & & \\
\hline Research site & $31^{* *}$ & & & & 0.05 & $0.81^{*}$ \\
$\quad$ In Turkey & 10 & -0.17 & 0.14 & $-0.45 ; 0.09$ & & \\
$\quad$ Outside of Turkey & 21 & -0.13 & 0.08 & $-0.29 ; 0.02$ & & $0.70^{*}$ \\
\hline Stakeholder type & $27^{* *}$ & & & & & \\
$\quad$ High school students & 3 & -0.11 & 0.07 & $-0.26 ; 0.04$ & & \\
$\quad$ Undergraduates & 11 & -0.09 & 0.14 & $-0.37 ; 0.17$ & & \\
$\quad$ Professional athletes & 10 & -0.05 & 0.13 & $-0.54 ;-0.01$ & & \\
Trainers & 3 & -0.134 & 0.37 & $-0.79 ; 0.68$ & & \\
\hline
\end{tabular}

$* \mathrm{p}<0.05$ significance level

** Two or fewer subgroups were not included in the moderator analysis.

heterogeneity [30, 42]. $\mathrm{I}^{2}$ shows the ratio of residual variance to the total variance concerning effect size. Unlike the Q statistic, the $\mathrm{I}^{2}$ statistic is not affected by the number of studies. In the $\mathrm{I}^{2}$ interpretation, $25 \%$ shows low heterogeneity, $50 \%$ moderate heterogeneity, and $75 \%$ high heterogeneity [43]. The model was converted to a random model as the homogeneity tests $\left(\mathrm{Q}\right.$ and $\left.\mathrm{I}^{2}\right)$ for the gender variable showed high heterogeneity among the studies. Moderator analysis (Mixed effect analysis) was performed to identify the reasons for the heterogeneity (Table 3).

Borenstein et al. recommend moderator analysis to 
identify the reasons for heterogeneity among studies. Therefore, we analyzed some moderators to explore the causes of the heterogeneity [44].

The analysis showed that research site, research type, and stakeholder type did not play a moderating role in the average effect size ( $\mathrm{p}>0.05)$. A meta-regression analysis was conducted to determine whether publication year was a moderator. The results showed that more recent studies had smaller effect sizes in favor of men. However, the difference was statistically insignificant (coefficient= [.02]; $\mathrm{p}=.22$ ). Another meta-regression analysis was performed to identify whether the sample size was a moderator. The results showed that sample size had no moderating effect on the effect sizes (coefficient $=.00$; $\mathrm{p}=.96)$.

\section{Discussion}

The study revealed that gender had a weak effect on the nutritional information of physical education and sports stakeholders, and women had a slightly higher level of knowledge than men. It also reveals that the research region, publication type and stakeholder types do not have a moderator effect.

We need to determine how much people know about nutrition to help them develop healthy dietary habits [45]. Akıl and Gürbüz found that male and female athletes had similar nutrition knowledge levels [46]. Süel, Şahin, Karakaya, and Savucu did not find a relationship between gender and nutrition knowledge among elite basketball players [47]. Earlier studies have reported similar results $[11,18,20,48]$.

Canbolat and Çakıroğlu reported that male trainers had higher nutrition knowledge scores than female trainers [19]. There are other studies with similar results [49-53]. Kiziltan focused on mineral consumption and determined that male students had more nutrition knowledge than their female counterparts [54]. Arazi and Hosseini observed that undergraduate male athletes had significantly more nutrition knowledge than non-collegiate female athletes [16].

Şahin and Taşkıran asked sailors to evaluate their nutrition knowledge. The results showed that female sailors had significantly more nutrition knowledge than their male counterparts. The results also showed that female sailors had significantly higher basic nutrition, nutrient-health knowledge, and food preference scores than males [55]. Citarella found that female ultramarathon runners had more nutrition knowledge than their male counterparts [56]. Heikkilä, Valve, Lehtovirta, and Fogelholm also reported that female endurance athletes and their trainers had more nutrition knowledge than their male counterparts [57].

Research shows that women have more nutrition knowledge than men [15,58-61]. Kunkel et al. investigated the effect of female peer educators on the nutrition knowledge of female collegiate athletes and found that peer nutrition education helped female collegiate athletes improve their nutrition knowledge [62]. According to some studies, women have more nutrition knowledge than men because they are more interested in subjects of nutrition and health $[7,10,61]$.

\section{Conclusions}

In this meta-analysis study, necessary searches were made by using online databases such as ULAKBIM, YÖK, Google Scholar, EBSCOhost, and Web of Science, and a synthesis was carried out by performing statistical operations with a total of 31 study data on the subject. In this study, which investigated the effect of gender on the nutritional information of physical education and sports stakeholders, it was concluded that women had higher knowledge at a weak level. Within the scope of the metaanalysis study, it was revealed that some independent variables that were thought to affect the overall effect size did not have a moderator effect. This study provides different perspectives to sports stakeholders, nutritionists and researchers who conduct research with new dimensions in order to maintain a healthy life. The following are recommendations based on our results:

-Educators and students should be provided with seminars, courses, and education programs addressing the results regarding the effect of gender on the nutrition knowledge of physical education and sports stakeholders.

- Future studies should investigate the effect of different moderators (parent education, income, athletic performance, etc.) on male and female stakeholders' nutrition knowledge levels.

-A further meta-analysis on the effect of gender on the dietary habits of stakeholders can contribute to the literature.

\section{Conflicts of Interest}

The authors declare no conflict of interest.

\section{References}

1. Erkan T. Nutrition in adolescents. Turkish Ped Arch. 2011;46(Special Edition):49-53. https://doi.org/10.4274/tpa.46.34

2. Baysal A. Nutrition. Ankara: Sahin Printing; 2007.

3. Erten M. Investigation of nutritional knowledge and habits of university students studying in Adlyaman [Master's Thesis]. Ankara: Gazi University; 2006.

4. Wardle J, Parmenter K, Waller J. Nutrition knowledge and food intake. Appetite. 2000;34:269-275. https://doi.org/10.1006/appe.1999.0311
5. Birkenhead K, Slater G. A review of factors influencing athletes' food choices. Sport Med. 2015;45:1511-1522. https://doi.org/10.1007/s40279-015-0372-1

6. Abood DA, Black DR, Birnbaum RD. Nutrition education intervention for college female athletes. $J \quad$ Nutr Educ Behav. 2004;36(3):135-137. https://doi.org/10.1016/S1499-4046(06)60150-4

7. Spendlove JK, Heaney SE, Gifford JA, Prvan T, Denyer GS, O'Connor HT. Evaluation of general nutrition knowledge in elite Australian athletes. Br J Nutr. 2012;107(12):1871-1880. https://doi.org/10.1017/S0007114511005125 
8. Rash CL, Malinauskas BM, Duffrin MW, Barber-Heidal K, Overton RF. Nutrition-related knowledge, attitude, and dietary intake of college track athletes. Sport J. 2008;11(1):48-54.

9. Heaney S, O'Connor H, Michael S, Gifford J, Naughton G. Nutrition knowledge in athletes: A systematic review. Int J Sport Nutr Exerc Metab. 2011;21:248-61. https://doi.org/10.1123/ijsnem.21.3.248

10.Spronk I, Kullen C, Burdon C, O'connor H. Relationship between nutrition knowledge and dietary intake. $\mathrm{Br} J$ Nutr. 2014;111:1713-26. https://doi.org/10.1017/S0007114514000087

11.Trakman GL, Forsyth A, Devlin BL, Belski R. A systematic review of athletes' and coaches' nutrition knowledge and reflections on the quality of current nutrition knowledge measures. Nutrients. 2016;8(9):570. https://doi.org/10.3390/nu8090570

12.Devlin B, Belski R. Exploring general and sports nutrition and food knowledge in elite male australian athletes. Int J Sport Nutr Exerc Metab. 2015;25:225-32. https://doi.org/10.1123/ijsnem.2013-0259

13.Zawila LG, Steib C-SM, Hoogenboom B. The female collegiate cross-country runner: Nutritional knowledge and attitudes. J Athl Train. 2003;38(1):67-74.

14.Jacobson HB, Sobonya C, Ransone J. Nutrition practices and knowledge of college varsity athletes: a follow-up. J Strength Cond Res. 2001;15(1):63-68. https://doi.org/10.1519/00124278-200102000-00011

15.Jessri M, Jessri M, Rashidkhani B, Zinn C. Evaluation of Iranian college athletes' sport nutrition knowledge. Int $J$ Sport Nutr Exerc Metab. 2010;20:257-63. https://doi.org/10.1123/ijsnem.20.3.257

16.Arazi H, Hosseini R. A comparison of nutritional knowledge and food habits of collegiate and noncollegiate athletes. SportLogia. 2012;8:100-107. https://doi.org/10.5550/sgia.120802.en.100A

17.Dunn D, Turner LW, Denny G. Nutrition knowledge and attitudes of college athletes. Sport J. 2007;10(4):45-53.

18. Rosenbloom CA, Jonnalagadda SS, Skinner R. Nutrition knowledge of collegiate athletes in a Division I National Collegiate Athletic Association institution. $J$ Am Diet Assoc. 2002;102(3):418-420. https://doi.org/10.1016/S0002-8223(02)90098-2

19.Canbolat E, Çakıroğlu FP. Determination of nutritional knowledge levels of trainers working in bodybuilding and fitness centers. CBU Physical Education and Sports Science Journal. 2016;11(2):83-91.

20.Çongar O, Özdemir L. Knowledge levels of physical education teachers about general nutrition and sports nutrition in Sivas city center. $C U$ Faculty of Medicine Journal. 2004;26(3):113-8.

21.Reason C. Determination of nutritional knowledge levels in endurance athletes. [Master's thesis]. Konya: Selcuk University; 2007.

22.Özdemir G, Özdilek C. Nutritional habits of students studying at Dumlupınar University Physical Education and Sports School and doing active sports. Dumlupinar University Sos Science Journal. 2015;26:1-9.

23.Göral K, Saygın Ö, Karacabey K. Investigation of nutrition knowledge levels of amateur and professional football players. International Journal of Human Science. 2010;7(1):837-56.

24.Kara N, Demir MK. Evaluation of postgraduate theses about classroom teachers in Turkey in terms of gender variable. Gazi Education Science Journal. 2020;6(3):300-16. https://doi.org/10.30855/gjes.2020.06.03.003

25.Karasar N. Scientific research method. Ankara: Nobel
Publication Distribution; 2005. $77 \mathrm{p}$.

26.Cumming G. Understanding the new statistics: Effect sizes, confidence intervals and meta-analysis. New York: Routledge, Taylor and Francis Group; 2012. https://doi.org/10.4324/9780203807002

27.Ellis PD. The Essential guide to effect sizes. New York: Cambridge University Press; 2010.

28.Hartung J, Knapp G, Sinha BK. Statistical meta-analysis with applications. New Jersey: Wiley Publishing Inc.; 2008. https://doi.org/10.1002/9780470386347

29. Winter A. A meta-analysis of school principals' views of administrators and teachers on the levels of demonstrating instructional leadership behaviors [ $\mathrm{PhD}$ Thesis]. Inonu University; 2013.

30.Y1ldırım N. Meta analysis. Scientific research methods in education from theory to practice. Mustafa Metin, editor. Ankara: Pegem Academy; 2014. P. 137-59.

31.Moher D, Liberati A, Tetzlaff J, Altman D, The PRISMA Group. Preferred reporting items for systematic reviews and meta-analyses:The PRISMAstatement. PLoSMed.2009;6(7). https://doi.org/10.1371/journal.pmed.1000097

32.Cohen J. Statistical power analysis for the behavioral sciences. 2nd ed. Hillsdale: NJ Lawrence Earlbaum Associates; 1988.

33. Miles MB, Huberman AM. Qualitative data analysis: An expanded sourcebook. California: Thousand Oaks; 1994.

34.Card NA. Applied meta-analysis for social science research. New York: The Guilford Press; 2012.

35.Petitti DB. Meta-analysis, decision analysis, and cost-effectiveness analysis. 2nd ed. New York: Oxford University Press; 2000. https://doi.org/10.1093/acprof:oso/9780195133646.001.0001

36.Landis JR, Koch GG. The measurement of observer agreement for categorical data. Biometrics. 1977;33:159-74. https://doi.org/10.2307/2529310

37.Cohen J. A Coefficient of Agreement for Nominal Scales. EducationalandPsychologicalMeasurement,1960;20:37-46. https://doi.org/10.1177/001316446002000104

38.Viera AJ, Garrett JM. Understanding interobserver agreement: the kappa statistic. Fam Med, 2005;37:360-3.

39.Hunter JE, Schmidt FL. Methods of meta-analysis: Correcting error and bias in research finding. 2nd ed. Thousand Oaks, CA: Sage Publication; 2004.

40.Hedges LV, Olkin I. Statistical methods for meta-analysis [Internet]. Orlando: Academic; 1985. Available from: http:// booksdescr.org

41.Cohen L, Manion L, Morrison K. Research methods in education. 7th ed. New York: Routledge; 2011.

42.Petticrew M, Roberts H. Systematic reviews in the social sciences: a practical guide [Internet]. Oxford: Blackwell Publishers Ltd.; 2005. Available from: http://booksdescr.org

43. Cooper H, Hedges LV, Valentine JC. Effect sizes for continuous data. In: Cooper H, Hedges LV, Valentıne JC, editors. The handbook of research synthesis and metaanalysis. 2nd ed. New York: Russell Sage Publication; 2009.

44.Borenstein M, Hedges LV, Higgins JPT, Rothstein HR. Introduction to Meta-Analysis. Chichester, UK: John Wiley \& Sons, Ltd; 2009. https://doi.org/10.1002/9780470743386

45.Zembat R, Kılıç Z, Ünlüer E, Çobanoğlu A, Usbaș H, Bardak $\mathrm{M}$. The role of pre-school education institutions in the child's acquisition of nutritional habits. $J$ Hacettepe Univ Fac Heal Sci. 2015;1(2):417-24.

46.Akıl M, Gürbüz U. Investigation of nutritional knowledge levels of athletes dealing with athletics branches. Physical 
Education and Sports Science Journal. 2010;7(1).

47.Süel E, Şahın I, Karakaya MA, Savucu Y. Nutritional knowledge and habits of elite basketball players. Firat University Health Science Medicine Journal. 2006;20(4):271-5.

48.Kaya N, Karacabey K, Kaya K, Kartal R. The comparison of the knowledge of nutrition, attitude and behaviours of the students who attend and do not attend at school sports activities. Online J Recreat Sport. 2016;5(4):15-20. https://doi.org/10.22282/v5.i4.02

49.Batmaz H. Development of nutritional knowledge level scale for adults and validity-reliability study [Master's Thesis]. Istanbul: Marmara University; 2018.

50.Webb MC, Beckford SE. Nutritional knowledge and attitudes of adolescent swimmers in Trinidad and Tobago. $J$ Nutr Metab. 2014;2014:1-7. https://doi.org/10.1155/2014/506434

51.Marak RC, Pamza SA, Luikham B. Knowledge of nutrition and attitude towards food supplements among sportsperson in Manipur. J Med Dent Sci. 2018;17(8):8-13.

52.Sedek R, Yih TY. Dietary habits and nutrition knowledge among athletes and non-athletes in National University of Malaysia (UKM). Pakistan J Nutr. 2014;13:752-9. https://doi.org/10.3923/pjn.2014.752.759

53.Özdoğan Y, Özçelik AO. Evaluation of the nutrition knowledge of sports department students of universities. $J$ Int Soc Sports Nutr. 2011;8(1):1-7. https://doi.org/10.1186/1550-2783-8-11

54.Kiziltan G. The effect of nutrition education on the nutritional knowledge level and nutritional status of students enrolled in the food and beverage management program of Başkent University. Journal of Nutrition and Diet. 2000;29(2):34-41
55.Şahin M, Taşkıran A. Examination of nutritional knowledge and habits of sailing athletes. Health and Sports Science Journal. 2020;3(2):47-54.

56.Citarella R, Itani L, Intini V, Zucchinali G, Scevaroli S, Kreidieh D, et al. Nutritional Knowledge and Dietary Practice in Elite 24-Hour Ultramarathon Runners: A Brief Report. Sports, 2019;7:44. https://doi.org/10.3390/sports7020044

57.Heikkilä M, Valve R, Lehtovirta M, Fogelholm M. Nutrition knowledge among young finnish endurance athletes and their coaches. Int J Sport Nutr Exerc Metab. 2018;28(5):522-527. https://doi.org/10.1123/ijsnem.2017-0264

58.Nikšić E, Joksimović M, Beganović E, Gardašević N. Differences in the degree of nutrition and body composition of boys and girls of pubertal age. Pedagogy of Physical Culture and Sports. 2021;25(1):39-6. https://doi.org/10.15561/26649837.2021.0106

59. Worme JD, Doubt TJ, Singh A, Ryan CJ, Moses FM, Deuster PA. Dietary patterns, gastrointestinal complaints, and nutrition knowledge of recreational triathletes. Am J Clin Nutr. 1990;51:690-697. https://doi.org/10.1093/ajen/51.4.690

60.Douglas PD, Douglas JG. Nutrition knowledge and food practices of high school athletes. $J$ Am Diet Assoc. 1984;84(10):1198-1202.

61.Parmenter K, Waller J, Wardle J. Demographic variation in nutrition knowledge in England. Health Educ Res. 2000;15(2):163-74. https://doi.org/10.1093/her/15.2.163

62.Kunkel ME, Bell LB, Luccia BH. Peer nutrition education program to improve nutrition knowledge of female collegiate athletes. $J$ Nutr Educ. 2001;33(2):114-5. https://doi.org/10.1016/S1499-4046(06)60175-9

\section{Information about the authors:}

Şakir Tüfekçi; (Corresponding Author); https://orcid.org/0000-0002-7815-5710; sakir.tufekci@inonu.edu.tr; Sports Management Department, Inonu University; Malatya, Turkey.

Hulusi Böke; https://orcid.org/0000-0002-5728-680X; yakamoz8386@gmail.com; Ministry of Education, Yaşar Öncan Secondary School; Malatya, Turkey.

Oğuzhan Altungül; https://orcid.org/0000-0002-2572-7324; oaltingul@firat.edu.tr; Sports Management Department, Elazığ University; Elazığ, Turkey.

\section{Cite this article as:}

Tüfekçi Ş, Böke $\mathrm{H}$, Altungül O. Examination of nutritional knowledge levels of physical education and sports stakeholders in gender variable: A systematic review and meta-analysis. Physical Education of Students, 2021;25(5):299-306. https://doi.org/10.15561/20755279.2021.0506

This is an Open Access article distributed under the terms of the Creative Commons Attribution License, which permits unrestricted use, distribution, and reproduction in any medium, provided the original work is properly cited http://creativecommons.org/licenses/by/4.0/deed.en

Received: 03.09.2021

Accepted: 06.10.2021; Published: 30.10.2021 